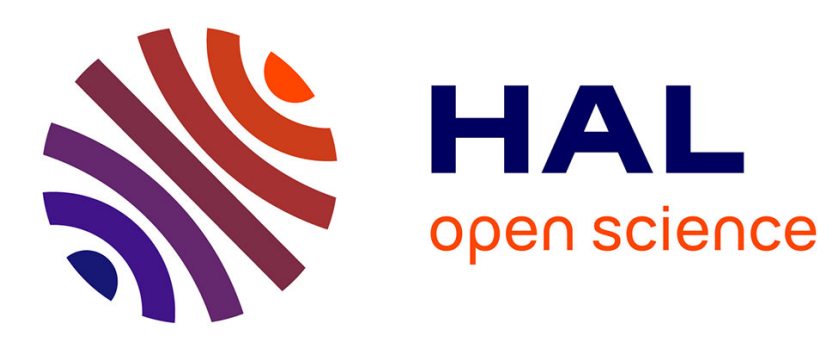

\title{
Capital Accumulation with Tangible Assets
}

Volker P. W. Böhm, George Vachadze

\section{- To cite this version:}

Volker P. W. Böhm, George Vachadze. Capital Accumulation with Tangible Assets. Journal of Economic Behavior and Organization, 2008, 68 (1), pp.248. 10.1016/j.jebo.2008.04.005 . hal-00618796

\section{HAL Id: hal-00618796 \\ https://hal.science/hal-00618796}

Submitted on 3 Sep 2011

HAL is a multi-disciplinary open access archive for the deposit and dissemination of scientific research documents, whether they are published or not. The documents may come from teaching and research institutions in France or abroad, or from public or private research centers.
L'archive ouverte pluridisciplinaire HAL, est destinée au dépôt et à la diffusion de documents scientifiques de niveau recherche, publiés ou non, émanant des établissements d'enseignement et de recherche français ou étrangers, des laboratoires publics ou privés. 


\section{Accepted Manuscript}

Title: Capital Accumulation with Tangible Assets

Authors: Volker Böhm, George Vachadze

PII: $\quad$ S0167-2681(08)00095-4

DOI: $\quad$ doi:10.1016/j.jebo.2008.04.005

Reference: $\quad$ JEBO 2206

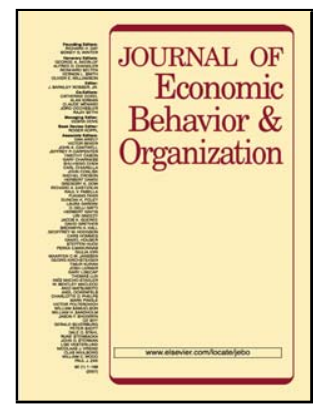

To appear in: Journal of Economic Behavior \& Organization

Received date: $\quad$ 8-2-2007

Revised date: $\quad 17-4-2008$

Accepted date: $\quad 18-4-2008$

Please cite this article as: Böhm, V., Vachadze, G., Capital Accumulation with Tangible Assets, Journal of Economic Behavior and Organization (2007), doi:10.1016/j.jebo.2008.04.005

This is a PDF file of an unedited manuscript that has been accepted for publication. As a service to our customers we are providing this early version of the manuscript. The manuscript will undergo copyediting, typesetting, and review of the resulting proof before it is published in its final form. Please note that during the production process errors may be discovered which could affect the content, and all legal disclaimers that apply to the journal pertain. 


\title{
Capital Accumulation with Tangible Assets ${ }^{1}$
}

\author{
Volker Böhm and George Vachadze ${ }^{2}$ \\ Department of Economics \\ Bielefeld University \\ P.O.Box 100131 \\ D-33501 Bielefeld \\ Germany
}

April 17, 2008

\begin{abstract}
The paper develops a neoclassical growth model with capital accumulation and a retradable tangible asset in an overlapping generations framework. It analyzes its effect on the dynamics of capital accumulation. Two period lived consumers hold portfolios consisting of real capital and the tangible asset. It is shown that the possibility of trading the tangible asset as an alternative to capital may cause the coexistence of stable steady states with high and low levels of capital and with disjoint basins of attraction. Thus, the so called poverty trap may appear purely endogenously generated as a consequence of asset trading alone. The possibility of the occurrence of the poverty trap is reduced as factors of production become more substitutable. However, the result is robust for continua of homogeneous as well as heterogeneous consumers.
\end{abstract}

Keywords: Capital accumulation, existence and stability of equilibria, portfolio choice, poverty trap, tangible asset

JEL classification: C62, D91, G11, G12, O11

\footnotetext{
${ }^{1}$ This paper was written as part of the project "International Financial Markets and Economic Development of Nations" supported by the Deutsche Forschungsgemeinschaft under contract BO 635/12-1.

${ }^{2}$ E-mail: vboehm@wiwi.uni-bielefeld.de, gvachadze@wiwi.uni-bielefeld.de
} 


\section{Introduction}

Widely observed poverty and its persistence in developing countries has motivated much of theoretical research to examine the reasons why countries with similar structural characteristics may converge to different equilibria in the long run. A common key feature of models deriving the so-called poverty trap ${ }^{3}$ is its self-perpetuating or self-reinforcing nature (i.e. economies will remain poor only because they are poor). Thus, poverty becomes its own cause and, most likely, countries are unable to escape the trap without any external assistance. In technical terms models with a poverty trap are characterized by the coexistence of stable steady states at high and low levels of income with disjoint basins of attraction. Therefore, convergence to these steady states depends on the initial capital stock.

Several plausible self-reinforcing mechanisms have been suggested in the literature through which initial conditions can determine the future evolution of an economy. One good illustration of how multiple steady states can emerge is provided by the presence of externalities associated with human capital formation. Various economic models have shown indeed that identical countries with different initial human capital may cluster around different equilibria. This can happen either as a result of a threshold externality in human capital as in Azariadis and Drazen (1990) or from imperfections in the credit market as in Galor and Zeira (1993). Financial underdevelopment was identified as another reason for a poverty trap in Saint-Paul (1992) and in Acemoglu and Zilibotti (1997). As these authors argue, the limited opportunity to diversify risk discourages entrepreneurs to make productive but risky investment. This leads to a limited set of traded financial instruments, and consequently it reduces the opportunity of risk diversification. Other structural reasons causing the economy to suffer from a poverty trap are summarized in Matsuyama (2008).

In this paper we reveal an additional mechanism that may cause a poverty trap to occur. Specifically we investigate the question whether the availability of a tangible asset as a portfolio opportunity to real capital investment can affect the dynamics of capital accumulation. The classical examples of such tangible assets are real estate, land, jewelry, gold, antique furniture, rare stamps, rare coins, oriental rugs, and other durable commodities. ${ }^{4}$ As pointed out by Meier and Baldwin (1957, pp. 307-8), Myrdal (1956,

\footnotetext{
${ }^{3}$ Examples include Banerjee and Newman (1993), Galor and Zeira (1993), Dercon (1998), and Mookherjee and Ray (2002, 2003); see also Azariadis and Stachurski (2004) or Carter and Barrett (2006) for reviews of the poverty trap literature.

${ }^{4}$ Indeed in most developed countries, consumers hold a significant part of their wealth in such tangible assets. For example, by 2001, this number was 40 percent for US households.
} 
pp. 202-3), Rosenberg (1960), and Wolff (1987), the existence of such an asset can be an obstacle to capital formation. The economic intuition of the mechanism is that the incentives of individual portfolio choice with tangibles as alternatives to real capital does not necessarily imply an investment in real capital for the economy as a whole when there is intertemporal trading among agents. In spite of the fact that consumers regard the acquisition of an asset as a form of personal saving and investment, the income spent on assets is diverted to consumption of those who use the asset as a store of value for ultimate consumption. Thus, the asset market induces an income redistribution between asset holders of succeeding generations, withdrawing funds from real investment. In other words, the introduction of a market for a tangible asset does not necessarily add to a society's supply of aggregate savings for real investment. To the extent that such an asset is used as a store of value to finance old consumption, it actually crowds out savings that might otherwise have been used to finance capital formation.

The role of a market of a productive asset on the dynamics of capital accumulation has been addressed in Böhm et al. (2006). There the asset is modelled as a regular share or equity of a producer with random dividend payments that originate from production shocks to a Cobb-Douglas technology. Consumer preferences are described by the CARA utility function, while the production shock is known and generated by the Gamma distribution. It is shown that the existence of an asset market can increase the number of stable steady states in the economy where one is associated always with zero capital. Thus, the asset crowds out physical capital completely. For sufficiently low initial capital, the economy will eventually converge to the steady state with zero capital. This happens despite the fact that the return on capital becomes unbounded. The force bringing the economy to the zero steady state is that for sufficiently low capital, the asset return increases so sharply that it becomes dominant to the return on capital investment. This creates an incentive for consumers to invest all of their wage income in the asset market as soon as the capital stock in the economy is sufficiently low. Consequently, the existing capital stock starts to deteriorate and declines eventually to zero.

This paper presents generalizations of these results in three directions. First, the results are derived for a simpler, non-stochastic economy with full depreciation of capital. Both assets are always valued positively, boundary steady states do not occur, and there is no need for randomness. Second, the occurrence of multiple steady states is shown to exists for the CES production function leading to interior long run levels of capital (in contrast to the findings in Böhm et al.). In addition, the role of factor substitution is studied for the existence of the poverty trap. Third, the results are shown to hold for a continuum of heterogeneous consumers. Thus, diversity of portfolio choices among consumers do not preclude the above effects. 
The paper is organized as follows. Section 2 introduces the model with a simpler, analytically tractable structure, capable of capturing the effect of the tangible asset on the dynamics of capital accumulation. Section 2.3 demonstrates the existence of a rational expectations equilibrium with and without an asset market. Section 2.4 discusses the dynamics of the economy and the possibility of the poverty trap. In section 3 we show that the result of the model persists when consumers are heterogeneous. Section 4 concludes.

\section{The Model}

Consider a market economy evolving in discrete time with a consumption sector, a production sector, and four markets operating in every period: a market for a single produced commodity usable for consumption and investment, markets for the two inputs, capital and labor, used to produce the output, plus a market for a tangible asset, the aggregate supply of which is normalized to unity and constant over time. The asset is traded between consumers in each period at a competitive market price without transaction costs. This asset could be interpreted broadly to include ownership of land, any tangible durable commodity, or any other asset not directly used (or usable) in production. All markets in the economy operate under perfect competition implying price taking behavior by all agents, consumers and producers. There is neither strategic behavior nor any information asymmetry.

\subsection{The Production Sector}

There is a single, infinitely lived firm in the economy, that produces a homogeneous commodity from capital and labor as inputs. The technology used for final commodity production in per capita terms is described by the CES production function of the form

$$
f(k):=\left\{\begin{array}{cc}
A\left(1-\alpha+\alpha k^{\rho}\right)^{\frac{1}{\rho}} & \text { if } \rho \neq 0 \\
A k^{\alpha} & \text { if } \rho=0
\end{array}\right.
$$

where $k \geq 0^{5}$ is capital per capita, $A>0$ is the Hicks neutral productivity level, $\alpha \in(0,1)$ is the capital share parameter, and $\rho \in(-\infty, 1]$ is the parameter of factor substitution.

Factor markets in the economy operate under perfect competition, implying that the factor rewards equal their marginal products respectively (i.e., the capital rental rate and

\footnotetext{
${ }^{5}$ In order to minimize notation, the index $t$ will be suppressed as much as possible. Variables without time subscript refer to an arbitrary time period $t$ while subscripts 1 and -1 refer to periods $t+1$ and $t-1$ respectively.
} 
the wage rate are given by $r(k):=f^{\prime}(k)$ and $\left.w(k):=f(k)-f^{\prime}(k) k\right)$. For simplicity we assume that capital depreciates fully during the production process; thus the capital stock in any period is entirely determined by new investment.

\subsection{The Consumption Sector}

The economy is inhabited by two period lived overlapping generations of consumers. In any given period, the two generations alive are referred to as young and old. Each generation consists of a continuum of homogeneous agents with unit mass. We assume that there is no population growth. Each young consumer is endowed with one unit of labor, which he supplies inelastically to the labor market in the first period of his life and for which he receives labor income $w$. Agents do not consume in the first period, but instead make investment in order to finance their second period consumption. They can transfer their wage income to the next period either by investing in physical capital or by purchasing the retradable asset. Since young consumers finance their investment entirely from their wage income, their budget constraint is

$$
p h+s \leq w,
$$

where $s$ denotes the amount of investment in capital and $h$ is the number of retradable assets purchased at price $p$. In the second period the agent receives $p_{1} h$ units of consumption goods from selling the asset plus $r_{1} s$ units of consumption goods as a return on his capital investment. Old agents do not leave bequests to future generations and consume their entire wealth. Therefore, final consumption $c_{1}$ is restricted to final wealth by

$$
c_{1} \leq p_{1} h+r_{1} s
$$

For simplicity we assume that consumer preferences are described by the linear utility function

$$
u(c, h):=c+\pi h,
$$

where $\pi>0$ is the valuation of the tangible commodity in terms of the consumption good. When making the portfolio decision, next period's rate of return on capital and the equity price, $\left(r_{1}, p_{1}\right)$ are unknown. It is assumed that consumers make point forecasts $\left(r^{e}, p^{e}\right)$ for both variables. In the subsequent analysis we will analyze exclusively the case when agents form rational expectations (i.e., agents' expectations about these quantities always coincide with actual realizations). Assumption (4) with budget constraints (2), (3), and $x \geq 0$ and $x p \leq w$ imply that asset demand is given by the following correspondence: 


$$
\varphi\left(w, r^{e}, p^{e}, p\right)=\left\{\begin{array}{ccc}
0 & \text { if } & p r^{e}>p^{e}+\pi \\
x \in\left[0, \frac{w}{p}\right] & \text { if } & p r^{e}=p^{e}+\pi \\
\frac{w}{p} & \text { if } & p r^{e}<p^{e}+\pi .
\end{array}\right.
$$

Thus, young consumers do not demand the asset for a sufficiently high price because of a more attractive return on capital. They invest all their wage income in the retradable asset market when its price/return is sufficiently low/high. If $p r^{e}=p^{e}+\pi$, consumers are indifferent between choosing investment in capital or in the retradable asset. In this case they may invest any fraction of their wage income in the asset market.

\subsection{Rational Expectations Equilibrium}

In order to study the effect of the tradability of the asset on capital accumulation, it is useful first to describe the dynamics of the economy when there is no market for the asset. Therefore, consider the situation when the ownership of the tangible asset is passed between generations through bequests without a market. In this case all young consumers invest all their wage income in capital. The accumulation in this case is described by the time one map

$$
k_{1}=w(k)
$$

where the wage function is given by

$$
w(k):=\left\{\begin{array}{ccc}
A(1-\alpha)\left(1-\alpha+\alpha k^{\rho}\right)^{\frac{1-\rho}{\rho}} & \text { if } \rho \neq 0 \\
A(1-\alpha) k^{\alpha} & \text { if } \rho=0 .
\end{array}\right.
$$

When $\rho \in[0,1]$ (i.e., when factors of production are highly substitutable), the economy has a unique positive steady state that is globally stable. When $\rho<0$ the wage function is no longer concave so that multiple steady states can arise. Therefore, in the remainder of the paper only the situation with $\rho \in[0,1]$ will be discussed, in order to identify the creation of an asset market as the sole source of multiple steady states.

Now assume that there exists a market where the asset is traded between generations. Let us show first that the market clearing price is uniquely determined for any given value of interest rate and price expectations, $\left(r^{e}, p^{e}\right)$ given by the function

$$
p=S\left(r^{e}, p^{e}\right):=\frac{p^{e}+\pi}{r^{e}} .
$$

Suppose $0<p r^{e} \neq p^{e}+\pi$. The demographic structure of the model implies that all assets sold by old consumers are bought by the young. Since the number of available assets in the 
economy is constant and normalized to unity, equation (5) implies that the asset market clearing price is $p=w$ and satisfies the inequality $p r^{e}<p^{e}+\pi$. But this is a contradiction. If consumers spend all their wage income in the asset market, then they do not make any capital investment, implying zero capital in the next period and an unbounded expected rate of return. Thus equation (8) is the unique deterministic function determining asset prices in any period for arbitrary interest rate and price expectations and positive wage income.

Definition 1 A Stationary Rational Expectations Equilibrium in the economy is a pair $(k, p) \in \mathbb{R}_{+}^{2}$, such that

- for given $k \in \mathbb{R}_{+}$, the asset price $p \in \mathbb{R}_{+}$is a fixed point of the price law under perfect foresight, $p=S(r(k), p)$,

- for given $p \in \mathbb{R}_{+}$, the capital stock is a fixed point of the capital accumulation equation, $k=A(k, p)$,

where $A(k, p):=w(k)-p$ and the rental rate of capital $r(k)$ is given by

$$
r(k):=\left\{\begin{array}{cl}
A \alpha k^{\rho-1}\left(1-\alpha+\alpha k^{\rho}\right)^{\frac{1-\rho}{\rho}} & \text { if } \rho \neq 0 \\
A \alpha k^{\alpha-1} & \text { if } \rho=0 .
\end{array}\right.
$$

The above definition implies that a Stationary Rational Expectations Equilibrium pair $\left(k^{*}, p^{*}\right)$, should satisfy the system of equations

$$
k=w(k)-p \quad \text { and } \quad r(k)=\frac{p+\pi}{p} .
$$

Then, equation (10) implies that the equilibrium capital stock, $k^{*}$, has to satisfy the following equation:

$$
\varphi(k):=\varphi_{1}(k)-\varphi_{2}(k)=0,
$$

where

$$
\varphi_{1}(k)=w(k)-k \quad \text { and } \quad \varphi_{2}(k)=\frac{\pi}{r(k)-1} .
$$

Let $\widehat{k}_{3}=\min \left\{\widehat{k}_{1}, \widehat{k}_{2}\right\}$, where $\widehat{k}_{1}$ denotes the unique positive solution of $w(k)=k$ and $\widehat{k}_{2}$ the solution of $r(k)=1$ if $A \alpha^{\frac{1}{\rho}}<1$ and $\widehat{k}_{2}=\infty$ if $A \alpha^{\frac{1}{\rho}} \geq 1$. It is clear that we are looking for a solution of equation $(11)$ in the interval $\left[0, \widehat{k}_{3}\right]$ since outside this interval the equilibrium asset price would be negative. Expressions (7) and (9) imply that $\varphi_{1}(k)$ is concave, first increasing and then decreasing, while $\varphi_{2}(k)$ is monotonically increasing. In addition, $\varphi(0)=w(0) \geq 0$ while $\varphi\left(\widehat{k}_{3}\right)<0$. Therefore, continuity of $\varphi$ implies that 


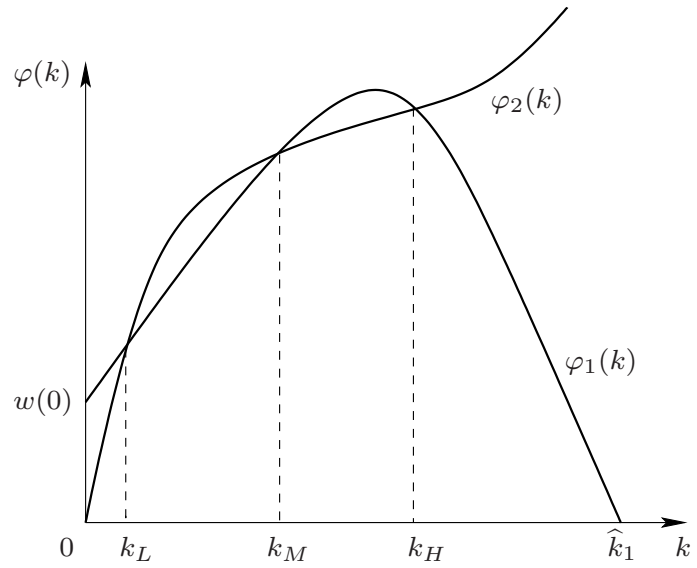

(a) $A \alpha^{\rho}<1$

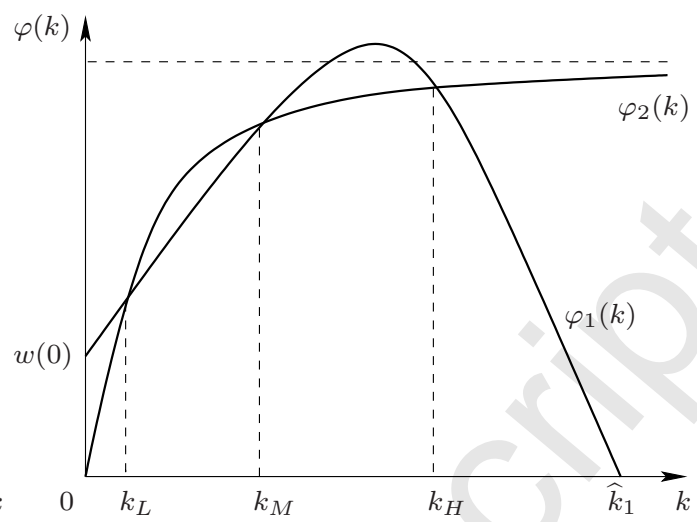

(b) $A \alpha^{\rho} \geq 1$

Figure 1: Multiple Solutions of $\varphi(k)=0$

equation (11) admits at least one solution on the interval $\left[0, \widehat{k}_{3}\right]$. Figure 1 shows the two possible configurations of the functions $\varphi_{1}(k)$ and $\varphi_{2}(k)$ when equation (11) has three solutions.

\subsubsection{Multiplicity of Stationary Equilibria}

The two functions $\varphi_{1}$ and $\varphi_{2}$ each determine a stationary price $p$ of the asset. Since they are non-linear one cannot determine analytically the parameter values for which there exist multiple steady states in the economy. Therefore, we rely on numerical procedures to plot parameter regions for which equation (11) can admit one, two, or three solutions. We choose the values given in Table 1 as a reference point.

\begin{tabular}{|c|c|c|c|}
\hline$A$ & $\alpha$ & $\rho$ & $\pi$ \\
\hline 4.00 & 0.70 & 0.00 & 1.00 \\
\hline
\end{tabular}

Table 1: Standard parameter set

Figure 2 displays regions where one (white) and three steady states (dark) exist in the economy. ${ }^{6}$ The situation with two steady states is not generic, occurring at a tangential contact between the two functions $\varphi_{1}$ and $\varphi_{2}$. This takes place when the parameters belong to the boundary of the dark regions of Figure 2. One observes that the economy has multiple steady states for intermediate values of $A, \alpha$ and $\pi$ and when the production function is of the Cobb-Douglas type $(\rho=0)$.

\footnotetext{
${ }^{6}$ All simulations are carried out using the software package ACRODYN specifically designed for the simulation of deterministic and stochastic dynamical systems; see Böhm (2003).
} 


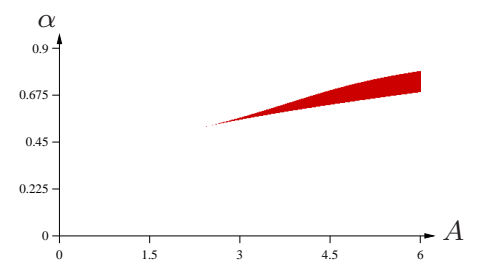

(a) $\pi=1.0, \rho=0.0$

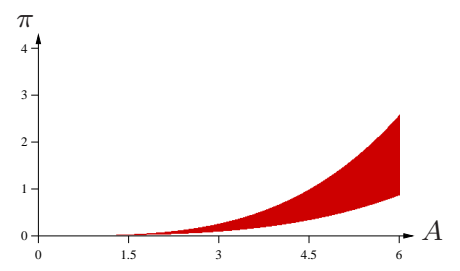

(b) $\alpha=0.7, \rho=0.0$

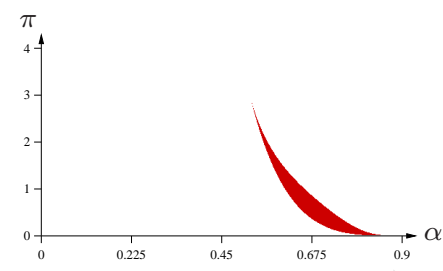

(c) $A=4.0, \rho=0.0$

Figure 2: Multiple Steady States for $\rho=0.0$

Figure 3 shows the set of parameters where multiple steady states exist as factor substitutability parameter increases. As factors become more substitutable, the possibility of having multiple steady states decreases. One can show analytically that the function $\varphi(k)$ becomes linear when factors are perfect substitutes, $\rho=1$, implying a unique steady state for all values of the parameters.

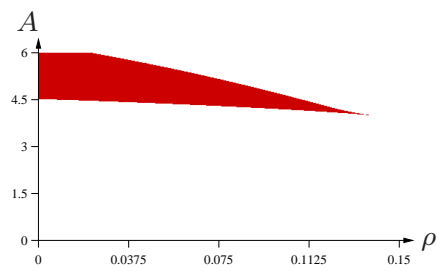

(a) $\alpha=0.7, \pi=1.0$

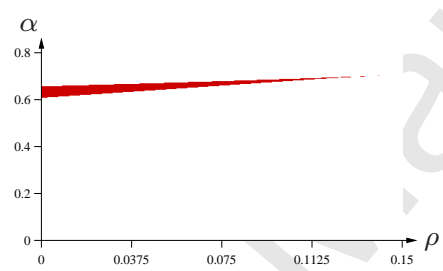

(b) $A=4.0, \pi=1.0$

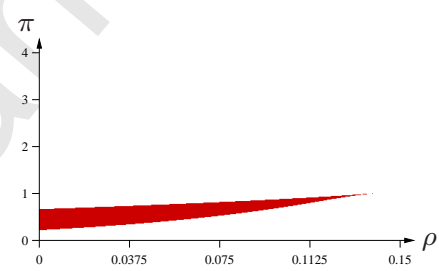

(c) $A=4.0, \alpha=0.7$

Figure 3: Role of Factor Substitution on Multiplicity

Summarizing the result for steady states, the economy, in which agents can trade the tangible asset in a market, may have multiple steady states with rational expectations, all of which have lower levels of capital than the steady state in the economy where the ownership is passed between generations through bequests. As factors become more substitutable the set of parameters for which the economy has multiple steady states shrinks. Multiplicity disappears for sufficiently large values of the parameter $\rho$.

\subsection{Rational Expectations Dynamics}

In order to analyze the dynamics of the economy we consider the so-called minimum state variable solution (MSV). From the dynamical point of view, this corresponds to the associated functional rational expectation equilibrium discussed and used in the literature ${ }^{7}$. Suppose there exists a function $P($.) that determines the asset price $p$ as a function of existing capital stock $k$ alone. Then the accumulation function implies that next period's

\footnotetext{
${ }^{7}$ See for example, Spear (1988), McCallum (1998, 1999), Böhm and Wenzelburger (2004), Wenzelburger (2006)
} 
capital stock is given by

$$
G(k):=w(k)-P(k) .
$$

Using the function $G$, one can derive the associated predicted price $p^{e}=P(G(k))$ and the predicted interest rate $r^{e}=r(G(k))$. In order for the predictions to be perfect, they should be consistent with the price law; that is, they should satisfy the following functional equation:

$$
P(k):=S(r(G(k)), P(G(k)))=\frac{P(G(k))+\pi}{r(G(k))} .
$$

In other words, a state price function $P$ that satisfies equation (14) for all $k$ induces perfect foresight for any two successive periods. In the sequel, equations (13) and (14) will be referred to as the capital accumulation equation and the price equation. These equations guarantee perfect foresight along any orbit of the economy.

Proposition 1 Suppose there is a continuous solution $(P, G)$ of the system of functional equations (13) and (14). Then $G$ is monotonically increasing.

Proof: Suppose there exists $k_{1}$ and $k_{2}$ such that $k_{1} \neq k_{2}$ and $G\left(k_{1}\right)=G\left(k_{2}\right)$. Then equation (14) implies that $P\left(k_{1}\right)=P\left(k_{2}\right)$, and (13) implies that $w\left(k_{1}\right)=w\left(k_{2}\right)$ which is a contradiction. Therefore $G$ is injective. Continuity and injectivity of $G$ implies its monotonicity. Suppose $G$ is monotonically decreasing. Then equation (13) implies that $P$ must be monotonically increasing. If $G$ is decreasing and $P$ is increasing, then equation (14) implies that $P$ must be decreasing, which is a contradiction. Therefore, $G$ is a monotonically increasing function.

It is clear that $G(0)=P(0)=0$ when $\rho=0$. However, $0<G(0)<w(0)=A(1-\alpha)^{\frac{1}{\rho}}$ for $\rho \in(0,1]$. If $G(0)$ were 0 , then equation (14) implies, that $P(0)$ is also 0 . But this is in contradiction with equation $(13)$ because $P(0)+G(0)=w(0)=A(1-\alpha)^{\frac{1}{\rho}}>0$. In addition we have that

$$
\lim _{k \rightarrow \infty} \frac{G(k)}{k} \leq \lim _{k \rightarrow \infty} \frac{w(k)}{k}=0,
$$

implying the existence of at least one positive steady state.

Figure 4 shows possible configurations of the time one map $G$. Panels (a) and (c) depict cases when there is a unique equilibrium. As parameters change (see Figures 2 and 3) the unique steady state undergoes a saddle-node bifurcation and two stable equilibria emerge as the only possible outcomes as shown in panel (b). This is the situation when a poverty trap occurs. Depending on initial capital, the economy converges either to $k_{L}$ or $k_{H}$. 


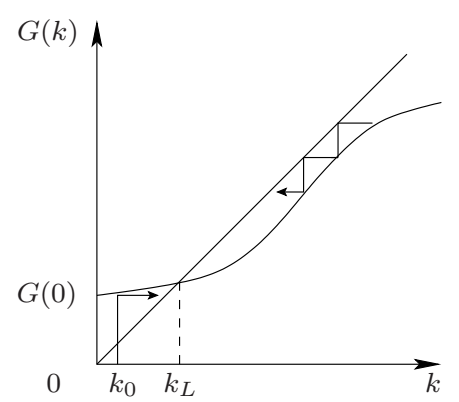

(a)

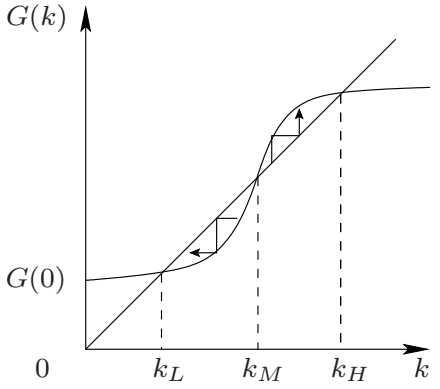

(b)

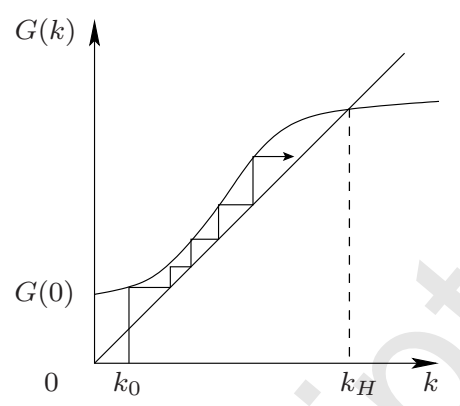

(c)

Figure 4: Three Configurations of the Time One Map

\section{Heterogeneous Consumers}

The previous analysis assumed that consumers had identical valuations of the tangible asset. This section extends the result of the occurrence of a poverty trap to situations when consumers have heterogeneous valuations.

Let $(I, \mathcal{I}, \mu)$ denote the space of agents with $I=[0,1]$ the unit interval, $\mathcal{I}$ the Lebesgue $\sigma$-algebra of subsets of $I$, and $\mu$ the uniform measure on $I$. A mapping $\pi: I \rightarrow[\underline{\pi}, \bar{\pi}]$ associates with each agent his individual valuation. Without loss of generality agents are ranked in such a way that $\pi(i)$ is a strictly increasing function. Then the inverse function of $\pi$ describes the distribution of agents' valuations of the asset:

$$
\mathbb{P}(\pi(i) \leq x)=\mathbb{P}\left(i \leq \pi^{-1}(x)\right)=\mu\left(\left[0, \pi^{-1}(x)\right]\right)=\pi^{-1}(x) .
$$

In the next section we investigate equilibrium allocations in a heterogeneous agents' economy and show that the possibility of multiple equilibria is preserved after introducing heterogeneity of valuations.

\subsection{Multiplicity of Equilibria}

Consider stationary equilibrium allocations in the economy with heterogeneous agents. Since agents differ in their valuations, there must exist a threshold agent $\eta^{*}$ such that all agents with $i<\eta^{*}$ invest only in capital while agents with $i>\eta^{*}$ buy the tangible asset. Agent $i=\eta^{*}$ must be indifferent between capital and asset market investment. This implies that the equations given in (10) can be rewritten as follows:

$$
k^{*}=\eta^{*} w\left(k^{*}\right) \text { and } p^{*}=\left(1-\eta^{*}\right) w\left(k^{*}\right) \quad \text { and } \quad r\left(k^{*}\right)=\frac{p^{*}+\pi\left(\eta^{*}\right)}{p^{*}} .
$$

Eliminating $\left(p^{*}, \eta^{*}\right)$ from equation (17) it follows that in equilibrium $k^{*}$ must satisfy

$$
w(k)-k=\frac{\pi\left(\frac{k}{w(k)}\right)}{r(k)-1} .
$$


In equilibrium the asset price and the fraction of agents who invest only in the capital market are determined by the following system:

$$
p^{*}=w\left(k^{*}\right)-k^{*} \quad \text { and } \quad \eta^{*}=\frac{k^{*}}{w\left(k^{*}\right)} .
$$

Equation (18) is analogous to (10). In the homogeneous case $\pi(i)$ was a constant function with $\pi(i)=\pi$ for any $i \in I$. With heterogeneous agents the function $\pi$ becomes an important determinant of multiple equilibria. Since $\pi$ is strictly increasing it follows that the right hand side of equation (18) is also strictly increasing and

$$
\frac{\pi\left(\frac{k}{w(k)}\right)}{r(k)-1} \in\left[\frac{\underline{\pi}}{r(k)-1}, \frac{\bar{\pi}}{r(k)-1}\right] \text {. }
$$

The feature of Figure 1 can be used to demonstrate that multiple equilibria can occur. Panels (a) and (b) of Figure 5 display the function $\phi(k)=(w(k)-k)(r(k)-1)$ for $\rho>0$ and the possibility of multiple equilibria. The existence of multiple equilibria depends on the particular nonlinear configuration of the functions $\phi(k)$ and $\pi\left(\frac{k}{w(k)}\right) \cdot \pi(x)$ is an increasing function, with $\pi(0)=\underline{\pi}$ and $\pi(1)=\bar{\pi}$. On the other hand, when $\rho \geq 0$, the function $\frac{k}{w(k)}$ is increasing as well. This implies that $\pi\left(\frac{k}{w(k)}\right)$ is also an increasing function. Figure 5.(b) displays the situation when there are multiple equilibria with heterogeneous agents. Observe that for any distribution of agents' valuation, the economy always has at least one equilibrium.

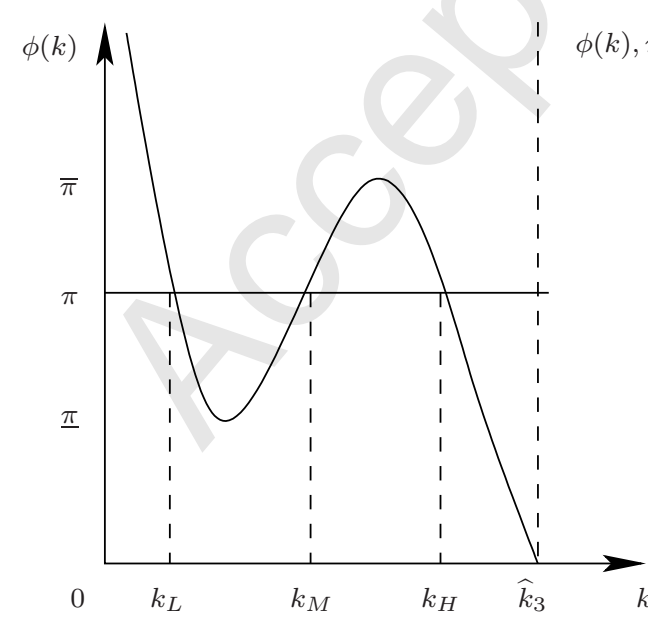

(a) Homogeneous Agents

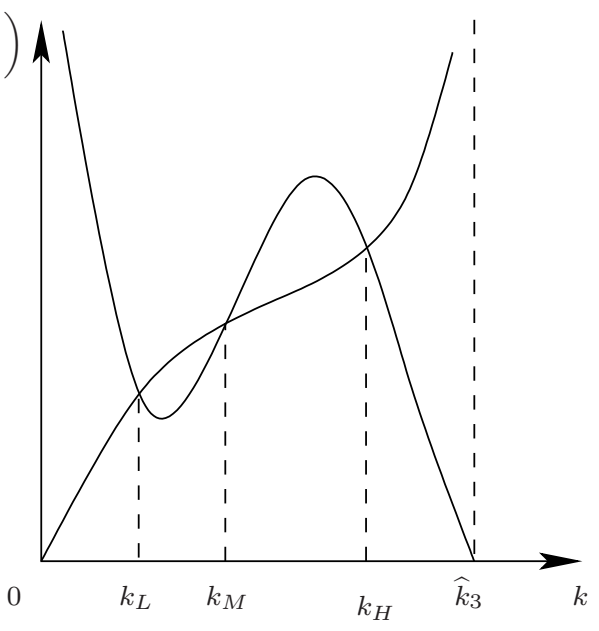

(b) Heterogeneous Agents

Figure 5: Possibility of Multiple Equilibria: $\rho>0$ 


\subsection{Dynamics}

Suppose there exists a price function $p=P(k)$ determining the asset price in any period as a function of the existing capital stock. Then the capital accumulation function is again given by

$$
G(k):=w(k)-P(k) .
$$

Using the capital accumulation function $G$, one can derive the price and the interest rate predictors. For the price predictor to be perfect it must be consistent with the third equation of system (17): that is, it should satisfy the following functional equation:

$$
P(k):=S(P(G(k)), r(G(k)), k)=\frac{P(G(k))+\pi(\eta(k))}{r(G(k))},
$$

where $\eta(k)$ is the fraction of agents who make capital investment:

$$
\eta(k):=\frac{G(k)}{w(k)}
$$

As before, capital accumulation is again one dimensional, and price and interest rate predictors guarantee perfect foresight along any orbit of the economy.

Proposition 2 Suppose there is a continuous solution $(P, G)$ of the system of functional equations (21), (22), and (23). Then $G$ is monotonically increasing.

Proof: We can again use the same logic as in Proposition 1. Suppose there are two different $k_{1}$ and $k_{2}$ such that $k_{1}>k_{2}$ and $G\left(k_{1}\right)=G\left(k_{2}\right)$. Then (22) and (23) imply that $\eta\left(k_{1}\right)<\eta\left(k_{2}\right)$ and consequently $P\left(k_{1}\right)<P\left(k_{2}\right)$. Together with equation (21) this implies that $w\left(k_{1}\right)=P\left(k_{1}\right)+G\left(k_{1}\right)<P\left(k_{2}\right)+G\left(k_{2}\right)=w\left(k_{2}\right)$. But this yields a contradiction because for $k_{1}>k_{2}, w\left(k_{1}\right)>w\left(k_{2}\right)$. Hence $G$ is injective. Continuity and injectivity of $G$ implies its monotonicity. Suppose $G$ is a monotonically decreasing function. Then equation (21) implies that $P$ is a monotonically increasing function, and consequently equation (22) implies that $P$ is a monotonically decreasing function, a contradiction. Therefore, $G$ is monotonically increasing.

The above proposition shows that one obtains the same configuration of the capital accumulation time-one map as in the economy with homogeneous agents. When there are multiple equilibria, the economy converges to either a high or a low steady states depending on the initial condition. 


\section{Conclusion}

In the paper we propose an asset based approach to explain poverty and poverty dynamics in the overlapping generations framework. We demonstrate that the tradeoff between investment in productive capital and tangible assets can create a potential for a poverty trap. If the asset market is inactive and ownership is transferred between generations through bequests, the economy has a unique and globally stable equilibrium to which all capital accumulation paths converge. As soon as agents are allowed to trade the tangible asset, crowding out of productive capital by the asset occurs, implying lower levels of capital, of income, and of welfare in the long run. In addition, second order properties (of curvature) of the wage and of the return function cause an S-shaped time-one map under rational expectations with possible stable equilibria at high and low levels of capital as shown in Figure 4. The existence of multiple equilibria implies at least one unstable steady state, defining a critical threshold level of capital depicted by $k_{M}$ in panel (b) of Figure 4. These effects are caused, among other things, by the elasticity of substitution. As the latter goes to plus infinity, multiple steady states no longer appear.

The assumptions of the parameterized model describe a truly simple class of economies for which these properties hold generically. Capital depreciates 100 percent, there is no randomness in the economy, and rational expectations occur along any orbit. Thus, it is not surprising that for more complex economies with random production, with more realistic capital formation (as in Böhm et al), and with consumer heterogeneity, the results hold true as well. They confirm once more that an increase of portfolio opportunities often designed as a move toward completing an otherwise incomplete market system actually can lead individually rational investment strategies astray from a social point of view. They cause crowding out of desirable real investment opportunities and may cause instabilities of desirable steady states. Thus, there is no reason to believe that an invisible hand operating in asset markets may lead an economy from a low level of capital to a welfare optimum. Market returns, perfect competition, and perfect foresight are no guarantee for Pareto improving trades for economies with asset markets. They may in fact cause over consumption when real investment is the most needed strategy to avoid poverty. Thus, a benevolent economist advisor should have second thoughts before suggesting the creation of an asset market in an underdeveloped country. 


\section{References}

Acemoglu, D., Zilibotti, F., 1997. Was prometheus unbounded by chance? Risk, diversification and growth. Journal of Political Economy 105, 709-751.

Azariadis, C., Drazen, A., 1990. Threshold externalities in economic development. Quarterly Journal of Economics 105, 501-526.

Azariadis, C., Stachurski, J., 2004. Poverty traps. In: Aghion, P., Durlauf, S., (Eds.). Handbook of Economic Growth. Amsterdam: North-Holland, 295-384.

Banerjee, A., Newman, A., 1993. Occupational choice and the process of development. Journal of Political Economy 101, 274-298.

Böhm, V., 2003. NACRODYN - The Handbook. Discussion Paper no. 498, Department of Economics, Bielefeld University, Bielefeld.

Böhm, V., Kikuchi,T., Vachadze, G., 2006. On the role of equity for the dynamics of capital accumulation. Discussion Paper no. 551, Department of Economics, Bielefeld University, Bielefeld.

Böhm, V., Wenzelburger, J., 2004. Expectational leads in economic dynamical systems. In: Barnett, W., Deissenberg, C., Feichtinger, G., (Eds.). Economic Complexity: Nonlinear Dynamics, Multi-Agents Economies, and Learning, Vol. 14 of International Symposia in Economic Theory and Econometrics. Amsterdam: Elsevier Science, 333-361.

Carter, M. R., Barrett, C. B., 2006. The economics of poverty traps and persistent poverty: An asset-based approach. Journal of Development Studies 42, 178-199.

Dercon, S., 1998. Wealth, risk and activity choice: Cattle in Western Tanzania. Journal of Development Economics 55, 1-42.

Galor, O., Zeira, J., 1993. Income distribution and macroeconomics. Review of Economic Studies 60, 35-52.

Matsuyama, K., 2008. Poverty traps. In: Durlauf, S. N., Blume, L. E., (Eds.). The New Palgrave Dictionary of Economics, 2nd Edition. Basingstoke, Hampshire: Palgrave Macmillan, 99-99.

McCallum, B. T., 1998. Solutions to linear rational expectations models: a compact exposition. Economics Letters 61, 143-147. 
McCallum, B. T., 1999. Role of the minimal state variable criterion in rational expectations models. International Tax and Public Finance 6, 621-639.

Meier, G., Baldwin, R., 1957. Economic Development: Theory, History, Policy. New York: Wiley.

Mookherjee, D., Ray, D., 2002. Contractual structure and wealth accumulation. The American Economic Review 92, 818-849.

Mookherjee, D., Ray, D., 2003. Persistent inequality. Review of Economic Studies 70, 369-393.

Myrdal, G., 1956. An International Economy, Problems and Prospects. New York: Harper.

Rosenberg, N., 1960. Capital formation in underdeveloped countries. The American Economic Review 50, 706-715.

Saint-Paul, G., 1992. Technological choice, financial markets and economic development. European Economic Review 36, 763-781.

Spear, S., 1988. Existence and local uniqueness of functional rational expectations equilibria in dynamic economic system models. Journal of Economic Theory 44, 124-155.

Wenzelburger, J., 2006. Learning in Economic Systems with Expectations Feedback. Lecture Notes in Economics and Mathematical Systems, 555. Berlin: Springer.

Wolff, E. N., 1987. Growth, Accumulation, and Unproductive Activity. Cambridge, UK: Cambridge University Press. 